\title{
Intervención profesional de trabajadores sociales de la universidad del Quindío, Colombia. Asuntos epistemológicos, metodológicos y ético-políticos
}

\author{
Ana María Gil-Ríos \\ Magíster en Educación y Desarrollo Humano. Trabajadora social \\ Universidad del Quindío. Armenia, Colombia \\ https:/ / orcid.org/0000-0002-6507-0195• amgil@uniquindio.edu.co
}

Resumen

Se analizan los procesos de intervención que Trabajadores Sociales egresados de la Universidad del Quindío, realizan con comunidades diversas, en el departamento. Con una metodología cualitativa soportada en teorías críticas, interculturales y decoloniales, se buscó construir conocimiento colectivamente con los actores que formaron parte del proceso. Para ello se estableció entre todos los participantes una relación horizontal y se buscó consolidar una comunidad de aprendizaje en la que todos fueron asumidos como sujetos de conocimiento. El proceso investigativo se vivió en seis ciclos o momentos, desde la conformación del equipo de investigación, hasta la socialización y divulgación de los hallazgos. Se identificó que los profesionales a nivel epistemológico-teórico, tienden a ubicarse para su intervención en una matriz comprensiva y crítica, hacen uso de una pluralidad teórico conceptual y a su vez cuestionan y problematizan la teoría e invitan a reconocer los saberes que emergen del contexto. En lo metodológico, privilegian la participación, lúdica y experiencia, al igual que los métodos genéricos para su intervención. Con respecto a la dimensión ético-política, hacen referencia a principios y dilemas éticos, construyen una noción de sujeto para la intervención y ofrecen pistas para la reflexión sobre el proyecto político profesional. Se concluye en la necesidad de fortalecer la producción de conocimiento endógeno de la profesión, para apuntar al fortalecimiento disciplinar.

Palabras clave: Trabajo Social; Intervención profesional; Referentes teóricos, metodológicos y ético-políticos.

Recibido: 09/07/2021 | Aprobado: 08/10/2021 | Publicado: 01/01/2022

(c) (i) (2) Esta obra está bajo una Licencia Creative Commons Atribución-NoComercial-

Financiación o proveniencia del artículo: Artículo derivado del proyecto de investigación La intervención profesional que realizan Trabajadores Sociales egresados de la Universidad del Quindio, con comunidades diversas, avalado por la Universidad del Quindío, Colombia. Periodo de ejecución: 2018-2019.

¿Cómo citar este artículo? / How to quote this article?

Gil-Ríos, A. M. (2022). Intervención profesional de trabajadores sociales de la universidad del Quindío, Colombia. Asuntos epistemológicos, metodológicos y ético-políticos. Prospectiva. Revista de Trabajo Social e intervención social, (33), 235-258. doi: 10.25100/prts.v0i33.11443. 
Gil-Ríos

\title{
Professional Intervention by Social Workers from the Universidad del Quindío, Colombia. Epistemological, Methodological and Ethical-Political Issues
}

\begin{abstract}
The study analyzes the intervention processes that Social Workers, graduated from the Universidad del Quindío, carry out with diverse communities in the region. We sought to build knowledge collectively with the actors who participated in the process using a qualitative methodology supported by critical, intercultural and decolonial theories. For this reason, a horizontal relationship was established among all the participants and an attempt was made to consolidate a learning community in which all were assumed as subjects of knowledge. The investigative process was composed of six cycles or moments, from the formation of the research team, to the socialization and dissemination of the findings. Results. It was identified that professionals, at the epistemological-theoretical level, tend to locate themselves in a comprehensive and critical matrix for their intervention, make use of a theoretical-conceptual plurality and in turn question and problematize the theory and recognize the knowledge that emerges from the context. In methodological terms, they favor participation, play and experience, as well as generic methods for their intervention. With regard to the ethical-political dimension, they refer to ethical principles and dilemmas, they construct a notion of the subject for the intervention, and they offer clues for the reflection of the professional political project. The need to strengthen the production of endogenous knowledge of the profession in favour of strengthening the discipline.
\end{abstract}

Keywords: Social Work; Professional intervention; Theoretical-epistemological, Metodological and Ethical-political dimension.

Sumario: 1. Introducción, 2. Metodología, 3. Hallazgos, 3.1 Abordajes epistemológicos y teóricos que sirven de base a la intervención profesional con comunidades diversas, 3.2 Aspectos metodológicos para la intervención profesional con comunidades diversas, 3.3 Dimensión ética y política que orienta la intervención profesional con comunidades diversas, 4. Conclusiones, 5. Referencias bibliográficas. 


\section{Introducción}

Los trabajadores(as) sociales en su praxis profesional abordan de forma permanente, diversidades sociales expresadas en lo cultural, lo étnico, lo religioso, el género y la generación así como en la pluralidad de capacidades de los habitantes en cuanto a nacionalidad y territorio. Es por esto que, desde esta investigación ${ }^{1}$, se reconoció la relevancia de la diversidad en el mundo de lo social, producto de las exigencias y luchas de grupos que históricamente han sido invisibilizados y que buscan reivindicar sus derechos. Sin embargo, también se considera que por tratarse de una cuestión ontológica, asumir lo humano desde una perspectiva homogénea resulta problemático y que, paradójicamente, esta es la idea que se encuentra en la base de algunas intervenciones sociales.

Los procesos de colonización y occidentalización han tenido influencia en una visión unívoca sobre los actores sociales que se refleja en discursos y prácticas de profesionales que, sin ser muy conscientes de ello, desconocen la existencia de otras epistemes, configuradas por mujeres, campesinos, indígenas, grupos étnicos (Mosquera-Rosero, 2005). El predominio de la racionalidad como forma válida de conocimiento, el individualismo y la competencia, han obstaculizado la construcción de interacciones sociales interculturales entre los sujetos y de estos con el entorno; hoy priman la competencia, el consumo y el desarraigo de lo tradicional, de los saberes ancestrales en acción (Mosquera-Rosero, 2005), que están cargados de experiencia y de contexto.

Teniendo en cuenta lo anterior y reconociendo que los Trabajadores(as) Sociales, interactúan constantemente en su praxis con sujetos, grupos, comunidades, organizaciones e instituciones caracterizadas por su diversidad, se construye la siguiente pregunta de investigación: ¿Cómo son los procesos de intervención que realizan Trabajadores(as) Sociales egresados de la Universidad del Quindio, con comunidades diversas?

Para responder a este cuestionamiento, los objetivos se enmarcaron en indagar acerca de los abordajes epistemológicos, teórico-conceptuales, metodológicos, y ético-políticos que sirven de base para la intervención profesional que han construido los Trabajadores(as) Sociales desde su experiencia.

Teóricamente la presente investigación retoma aportes de la decolonialidad del saber y la interculturalidad crítica con el fin de comprender las categorías claves para el estudio, como las diversidades sociales, y la intervención profesional del Trabajo Social, abordando en esta última, asuntos de orden epistemológico, metodológico y ético político. Sin embargo,

1 La presente investigación, formó parte de un trabajo en red con programas de Trabajo Social, pertenecientes a diferentes Universidades: Antioquia, La Salle y Caldas. A partir de este trabajo articulado, se construyó colectivamente una investigación macro, a la cual cada programa académico tributó desde sus intereses y especificidades. 
no todos los planteamientos y estrategias desarrolladas están escritos en textos. En concordancia con el marco teórico que transversaliza esta propuesta, hay saberes que forman parte del bagaje, experiencias y concepciones que tienen docentes, profesionales, personas diversas y son relevantes, aunque no sean conocimientos científicamente validados.

Se retoma la opción decolonial e intercultural para la construcción teórica, porque ofrece la posibilidad de romper las brechas entre la academia y la realidad social, entendiendo que pueden complementarse. Desde este lugar han de surgir novedosas formas de comprensión y acercamiento al otro y lo otro sin el lastre, del pensamiento formal. Según Gómez-Hernández (2015) la opción decolonial, como apuesta racional o de acción, permite también, comprender y visibilizar: a) las múltiples deshumanizaciones que se han presentado en el mundo y actualmente siguen vigentes, para colectivos que no encajan en los relatos de la modernidad (indígenas, afrodescendientes, campesinas, OSIGD-LGBTI) y, b) problematizar la destrucción ambiental indiscriminada con la intención desarrollista y civilizatoria en diversos contextos. A su vez, posibilita reconocer las huellas que ha dejado la herencia colonial en los seres humanos, la cual repercute en la forma de actuar y concebir las relaciones sociales desde una idea clasificatoria. Poblaciones y culturas con mayor importancia que otras; unas consideradas desarrolladas, modernas, superiores, por el contrario, otras, atrasadas, subdesarrolladas, incultas. En tal sentido, se configuran jerarquías de poder, que llevan a privilegiar a ciertos sujetos y vidas que encajan en los relatos de la modernidad y olvidar, ocultar, prescindir de las que no lo hacen.

Las herencias coloniales han ejercido control en las vidas, afectividades (GuerreroArias, 2010a) subjetividades e imaginarios sociales. También han impactado la forma de comprender lo político, económico, social, cultural y académico. La colonialidad del saber ha negado otras formas de construcción de conocimiento que no son avaladas por lo científico, imponiendo una hegemonía epistémica de la razón, como discurso de verdad para comprender la vida. Uno de los principales impactos de esta colonialidad, es la "negación de la afectividad en el conocimiento", (Guerrero-Arias, 2010a) el separar la razón de la emoción descartando el sentipensamiento en la construcción de saberes y escenarios académicos (Fals-Borda, 2009). La colonialidad del poder, referida a los aspectos estructurales de la dominación, construye lógicas incuestionadas en lo político, económico, cultural y social. En este sentido, no es posible considerar otras formas de organización de las sociedades. El capitalismo se presenta como único modelo económico para alcanzar desarrollo y progreso; en consecuencia, se arrasa con la naturaleza y se construye una relación extractiva con el ambiente, considerándolo recurso y mercancía. En lo cultural, se privilegian prácticas y costumbres globalizadas, que cumplan con los parámetros impuestos por la vida moderna. Las lenguas, los dialectos y otras espiritualidades son subestimadas, desconocidas y poco aceptadas. 
En tal sentido, la crítica decolonial, respaldada por corrientes como la pedagogía del oprimido, teorías de la liberación y de la dependencia, pensadores contemporáneos y latinoamericanos como Fals Borda, Quijano, Castro Gómez, Dussel, Escobar, Mignolo, Walsh, Lander, entre muchos otros, apuestan por un giro decolonial que conlleve a un cambio en las formas de ser y hacer de los sujetos colonizados (Maldonado-Torres, 2007). La decolonialidad, según Maldonado, es un proceso que busca “deshacer la realidad colonial y sus múltiples jerarquías de poder en su conjunto, lo que plantea la necesidad inmediata de trabajo a nivel subjetivo y estructural" (Maldonado-Torres, 2009, p. 686)

El Trabajo Social, tiene puntos de encuentro con la opción decolonial e intercultural (Gómez-Hernández, 2015) desde su intervención profesional, la cual orienta en principios y fines coherentes con un ideal emancipatorio, de garantía de derechos, dignidad humana y justicia social. Así mismo, comparte desde su praxis, el abordaje de problemas claves, entre ellos las consecuencias negativas que deja el capitalismo como modelo económico global, las múltiples desigualdades, violencias y pobrezas que enfrenta la mayor parte de población de nuestro país, el deterioro ambiental, (Gómez-Hernández, 2015) la represión de las protestas y luchas sociales, la concentración y colonialidad del poder y en consecuencia, el desconocimiento de otras formas de asumir lo social, cultural, económico, espiritual y político.

Por todo lo anterior, una práctica profesional en clave decolonial e intercultural se interesa en amalgamar los lazos sociales fragmentados por el neoliberalismo (Carballeda, 2005) y busca luchar contra las múltiples opresiones padecidas en los diversos contextos de la realidad social latinoamericana -patriarcado, colonialismo, racismo y capitalismo- con el fin de construir un diálogo intercultural en el que se escuchen las voces que han sido olvidadas o silenciadas por las estructuras de dominación y de poder perpetuadas.

\section{Metodología}

La investigación se enmarcó en un enfoque cualitativo. En coherencia con la opción decolonial e intercultural, la metodología ${ }^{2}$ propició la construcción colectiva de conocimiento entre los actores que formaron parte de la investigación. La relación que se estableció entre todos los participantes fue horizontal y se buscó consolidar una comunidad de aprendizaje en la que todos fueron asumidos como sujetos de conocimiento; además, se tuvieron en cuenta la diversidad de saberes y los pluralismos epistemológicos de los diversos participantes.

2 Se asumió la metodología en esta investigación como un camino abierto a la construcción mientras se transitaba por él. Un proceso reflexivo, creativo y no como un momento demarcado por pasos, etapas, lineal e inamovible. Su construcción fue colaborativa entre los y las integrantes de la red nacional de Trabajo Social Intercultural y Decolonial. 
Asumir una interacción no jerárquica y de imposición con los demás, como lo afirma Walsh (2008, p. 13) implica "una interculturalización epistémica, interpretativa e investigativa que permita un diálogo entre y con (no "sobre") actores, ciencias y perspectivas diferentes por su experiencia de vida dentro del sistema mundo modernocolonial".

En esta línea, la metodología fue de orden pedagógico, (todos conocemos, todos aprendemos, todos aportamos a la discusión) y la investigadora trató de reconocerse como una persona historizada, enraizada, consciente de su propia colonialidad, que también es transformada en el proceso de la investigación. Por este motivo, los principios metodológicos que orientaron el proceso fueron la problematización, el sentipensar, la conversación y la escucha.

El componente ético y bioético fue relevante en este hacer decolonial (Ortiz-Ocaña y Arias-López, 2019) ${ }^{3}$, para minimizar los riesgos e inconvenientes que se pudieran generar durante el proceso. La vinculación de los profesionales fue voluntaria y desde el trabajo con los consentimientos informados se logró dejar clara la confidencialidad, el interés de la propuesta y la importancia de su participación activa para la comprensión y reflexión sobre la praxis profesional.

Con respecto al proceso llevado a cabo en el trabajo de campo y en línea con los aportes de la decolonialidad y la interculturalidad, se asumió la espiral como herramienta para conocer. Desde la red se estableció colectivamente este camino porque no es lineal, ascensionista y permite la reflexividad a partir de cada uno de los ciclos en los que se mueve la investigación. La espiral cobra importancia para diversas culturas e implica nacimiento, finalización, re-nacimiento. Representa también rigurosidad, sistematicidad, complejidad y posibilidad de profundizar sobre el asunto que interesa conocer/problematizar.

Para iniciar el proceso se organizaron encuentros conversacionales con los y las profesionales a partir de ejes centrales de discusión acerca de las prácticas. Con respecto a la población participante, se contó con diversas experiencias de intervención profesional de trabajadores y trabajadoras sociales que se desempeñan laboralmente en el departamento del Quindío, con diversidades sociales. Los criterios cualitativos que se eligieron como aquellos que permiten una mayor inclusión de profesionales fueron los siguientes: a) Trabajadores(as) Sociales que hubieran realizado procesos de intervención directa en el departamento del Quindío, con comunidades diversas -aquellas que históricamente se han enmarcado en procesos de resistencia y visibilización de sus derechos- en los últimos 5 años.

3 Ambos autores, invitan a desobedecer la metodología de investigación tradicional, reflexionando acerca del legado colonial de las nociones, conceptos y prácticas propias a esta, para construir formas otras de "hacer decolonial”, configuradas a través de acciones y huellas que permitan transformarla y renombrarla. 
b) Que los procesos de intervención se realizaran en instituciones públicas y/o privadas del departamento. c) También podían participar profesionales sin una vinculación laboral directa, es decir, que su praxis estuviera relacionada con procesos organizativos en los cuales participaran de manera voluntaria.

El camino recorrido y orientado desde la ruta ofrecida por la espiral, como herramienta para conocer, se realizó en los siguientes ciclos:

a. Ciclo de conocimiento y articulación a la red Nacional: Se realizan primeras reuniones de encuentro y concertación con el equipo de la Red Nacional de Trabajo Social intercultural y decolonial, para formar parte del proceso de reflexión e investigación.

b. Ciclo de exploración conceptual y vivencial: se inició con la conformación de un grupo de estudio y semillero entre estudiantes y docentes del programa de Trabajo Social de la Universidad del Quindío. Desde allí se realizaron lecturas y ejercicios vivenciales para problematizar, reflexionar y conceptualizar sobre las diversidades sociales, la intervención profesional y la decolonialidad e interculturalidad como opción para el Trabajo Social; estos ejercicios sirvieron de insumo para cristalizar la propuesta de investigación.

c. Ciclo de consolidación de la propuesta: a partir del trabajo realizado en los ciclos anteriores y teniendo como base el proyecto de investigación macro, construido por la red, se consolidó la propuesta de investigación. Esta fue aprobada por convocatoria interna de la Universidad.

d. Ciclo de contacto con la población y encuentro/diálogo de saberes: el acercamiento y contacto con los trabajadores(as) sociales graduados, se realizó inicialmente a través de correo electrónico mediante una comunicación para informar acerca de la investigación, sus objetivos, justificación y criterios para participar (intervención profesional directa en el departamento del Quindío, con comunidades diversas). De este primer contacto se logró conformar una base de datos con información personal de los(as) interesados en participar. Seguidamente se realizó comunicación telefónica, para conversar nuevamente acerca de la propuesta y acordar encuentros presenciales con el fin de iniciar un proceso de familiarización. Este consistió en una conversación sobre la metodología, los criterios éticos, bioéticos y otras inquietudes. En este ciclo se fue construyendo un tejido colectivo que sirvió para acceder a otros contactos que podrían participar en el proceso. Los encuentros conversacionales fueron construidos rescatando una racionalidad emergente, que para el pensamiento fronterizo implica reconocer todas las experiencias cognitivas como inteligibles e importantes. Por este motivo, dichos encuentros estuvieron caracterizados por la conversación y la escucha. La premisa principal era evitar que estos espacios se redujeran a la implementación de técnicas para extraer información que 
posteriormente sería analizada. El compartir las experiencias profesionales se dio en el marco de una relación respetuosa y colaborativa. En un primer momento se realizó un encuentro de manera individual y, posteriormente, se realizaron encuentros grupales para continuar problematizando la praxis desde los aportes colectivos. Al finalizar el proceso, por la profundidad de los aportes y reflexiones realizadas, se contó con la participación de 12 graduados.

e. Ciclo de análisis, reflexión y círculos de palabra: la reflexión acerca de las experiencias de los y las profesionales, permitió la construcción de categorías centrales, las cuales fueron discutidas de manera colectiva con egresados promoviendo una interpretación conjunta. Estos espacios también se dieron con la red nacional de Trabajo Social Intercultural y decolonial: estudiantes, docentes y graduados aportaron a la reflexión sobre los procesos de investigación liderado por cada Universidad, lo cual permitió ampliar la comprensión de los hallazgos y la interpretación de los mismos colaborativamente.

f. Ciclo de Intercambios reflexivos: Para la socialización de los resultados, se participó en intercambios reflexivos en la red inter-universidades. También en un evento internacional acorde al tema de la investigación.

\section{Hallazgos}

La intervención profesional es un eje de análisis central en el Trabajo Social; se ha configurado como asunto medular en las discusiones profesionales a lo largo de su historia. Lo anterior, por ser el principal medio a través del cual, los trabajadores(as) sociales aportan a la transformación social en horizontes de justicia, dignidad y derechos humanos.

La intervención como concepto tiene múltiples significados: es polisémico, pero también polémico, en tanto su definición, deriva en acciones que pueden o no, estar en coherencia con la participación, las relaciones horizontales, el empoderamiento y la emancipación. Intervenir puede entenderse como mediar, interceder, acompañar, promover procesos. Pero también puede ser asumida como interponerse, irrumpir, controlar. Puede asociarse con autoridad para influir en situaciones inaceptables social y culturalmente. En suma, la intervención se da entre un profesional, agente interviniente, legitimado por dinámicas de poder, que busca incidir en otros-personas, usuarios, pacientes- para alcanzar cambios socialmente aceptados. (Mosquera-Rosero, 2005)

Retomando a Carballeda, (2005) la palabra intervención, proviene del latín "interventio" que significa "venir entre", mediar en una situación fenómeno o conflicto, para promover algún tipo de transformación. Sin embargo, ingresar al espacio del otro en busca de un cambio, puede darse desde diferentes lugares: la libertad, la potenciación, o la censura y el control. Por tanto, la intervención profesional puede ir en línea con lo coercitivo o 
emancipatorio. De allí la importancia de reconocer las contradicciones e impactos que cada una pueda generar.

Esta doble cara de la intervención (Carballeda, 2005), ha generado debate a nivel profesional, y en algunos casos ha motivado el tránsito hacia el uso de otros conceptos, en busca de resignificar la lógica autoritaria, jerárquica y de imposición que le subyace. Se ha propuesto sustituir la intervención por acción, práctica o actuación profesional (VélezRestrepo, 2003). Si bien cada concepto refiere énfasis o particularidades -en las acciones, en la teoría, en las relaciones- en común, hacen referencia a los procesos, estrategias, actividades que realizan profesionales apoyados en la investigación, la reflexión teórica y en el trabajo colaborativo con otros protagonistas del proceso, para el cumplimiento de objetivos y logros enmarcados en los principios y fines del Trabajo Social.

Autores como Rozas-Pagaza (2002), Cifuentes-Gil (2004), Corvalán (1996) VélezRestrepo (2003), refieren como elementos constitutivos de la intervención: la dimensión teórica, e investigativa que guía y fundamenta el accionar profesional; el componente ético, político y metodológico le confieren un carácter reflexivo, crítico y deliberado. Estos aspectos centrales reivindican la intervención del Trabajo Social como un proceso sistemático, consciente, que aporta a la construcción de conocimientos desde la acción. Su intención es transformadora, emancipatoria y se lleva a cabo en el marco de una relación respetuosa con sujetos capaces, activos y protagonistas. La especificidad del Trabajo Social es construida desde la integración de estos elementos constitutivos de la intervención (Travi, 2006) los cuales, a su vez, tributan a la consolidación de la identidad profesional.

Reflexionar acerca de los aspectos nucleares de la intervención -componentes epistémicos, teóricos, metodológicos, éticos y políticos- es un desafío permanente para los Trabajadores(as) Sociales. Problematizar la práctica desde la opción decolonial e intercultural, permite intervenciones fundamentadas, reflexivas, para afrontar las múltiples formas de opresión, exclusión e invisibilización a las que se enfrentan las diversidades sociales con las que cada profesional interactúa.

En este orden de ideas, al abordar con los trabajadores(as) sociales que formaron parte activa de este proceso, asuntos medulares de la intervención antes mencionados, se pudo plantear lo siguiente:

\subsection{Abordajes epistemológicos y teóricos que sirven de base a la intervención profesional con comunidades diversas}

La polifonía como característica principal de la intervención del Trabajo Social (MatusSepulveda, 2002), conlleva a que los y las profesionales recuperen para su praxis diversos aportes teóricos, y epistemológicos ofrecidos por la ciencia formal, que les permitan 
comprender y direccionar su acción. Sin embargo, también recurren a diversos saberes construidos en la práctica y por diversas poblaciones, como posibilidad para abordar de manera contextualizada y enraizada, las demandas y complejidades que enfrentan en su quehacer. Ello implica que para abordar los referentes teóricos y epistémicos que orientan la praxis profesional, sea necesario interpelar la relación jerárquica y estrecha establecida por el conocimiento científico, para dar paso a otras lecturas y formas de comprender la realidad construidas desde las epistemologías de frontera, que toman en cuenta lo contextual para la reflexión, y la construcción de una nueva geopolítica del conocimiento.

\section{Matriz epistemológica comprensiva y crítica como base de la intervención profesional}

Se encontró diversidad de perspectivas epistemológicas por parte de los trabajadores(as) sociales, para fundamentar su práctica, las cuales varían de acuerdo a las problemáticas abordadas, poblaciones y contextos en los que se desempeñan. Esto es coherente con un Trabajo Social plural, y la existencia de diversas formas de pensar, ser y hacer profesional. Sin embargo, desde sus relatos se evidencia una influencia marcada por las perspectivas comprensiva y crítica, lo cual da cuenta del interés emancipatorio de la praxis, y el compromiso por entender los lugares de exclusión, pobreza, violencias y múltiples injusticias que viven la mayoría de los grupos sociales con los que cada profesional se relaciona:

...jCarajo, no! digamos que es una mezcla porque al comienzo sentí que la universidad me había tirado al vacío y me había tirado de una manera equivocada a juzgar; entonces digamos que pensé en eso, pero me ayudó mucho, me encontré con un autor, bueno me encontré con el cubano, con Martí y me permitió ver que había otra opción y después me encontré con Santiago Castro, bueno, y ahí caí en cuenta, bueno tampoco es tan culpable los profes, todos caemos en el mismo rollo, entonces me tocó empezar a desaprender ... (Actor 3, comunicación personal, 19 diciembre de 2018)

... Todo el trabajo lo hice desde una postura constructivista que en un punto era muy posestructuralista digámoslo así, y eso trataba de articularlo a la fenomenología y a la hermenéutica, entonces como que esos cuatro elementos conjugados me permitían entender a mí que la realidad no era algo positivo, no era algo estático, (...) entonces yo entendía que yo como trabajador social no era esa persona que iba a decir: hagámoslo así, hagámoslo así (...). Yo entendía que yo como trabajador social era como una clase de digámoslo así, de posibilitador de algunas herramientas conjuntas. (Actor 7, comunicación personal, 26 de noviembre de 2018)

Se evidencia entonces, una orientación de los trabajadores sociales, a narrar su intervención profesional desde una perspectiva reflexiva, en donde la comprensión del otro y de su historia, cobran relevancia y reorientan la acción. Así mismo, coincidieron en reconocer a los actores sociales como protagonistas, como sujetos políticos con intereses, demandas particulares y capacidades para liderar sus propios procesos de intervención, poseedores de saberes que deben ser reconocidos y revalorizados (Mosquera-Rosero, 2005). 
...Yo me encontré con el texto de un profe Yanacona qué hablaba de epistemología y yo ¡carajo! que es esta locura, un indígena hablando de epistemología y lo que hizo fue decir ¡no! nosotros también tenemos epistemología, si ustedes lo quisieran ver, para nosotros la investigación es esto, con estos pasos y estos propósitos... (Actor 3, Comunicación personal, 19 diciembre de 2018)

Lo anterior, problematiza la negación de otras formas de conocimiento, que no forman parte de lo científico. Según Guerrero-Arias (2010b) esto debido a la colonialidad del saber, que ha impuesto un epistemo-centrismo hegemónico instrumental al poder, que niega la existencia de otras sabidurías desde las cuales se ha tejido la vida (p. 83). Es por ello que resulta necesario una desobediencia epistémica, que posibilite descolonizar el conocimiento y a su vez, incidir como proyecto transformador emancipatorio, en la desestructuración de la matriz colonia (Mignolo, 2010).

Mosquera-Rosero (2005) en esta dirección, propone asumir la intervención como una conversación con la cultura, como un espacio relacional y racional, donde se rescatan y construyen saberes, provenientes de la práctica -profesionales que se arriesgan a ir más allá de lo aprendido en su formación- y de las experiencias cotidianas de los sujetos y poblaciones con las que se interviene.

Para reconocer y valorar los saberes que emergen en la intervención, se requiere una apertura a las diversidades sociales y culturales, recuperar el sentipensamiento como posibilitador del diálogo y la escucha en clave intercultural. Además, construir una relación simétrica que vaya más allá de la aceptación o tolerancia de lo diferente, hacia la construcción de nuevas formas de relacionamiento y de vivir en sociedad. La interculturalidad crítica decolonial, le sugiere al Trabajo Social según Gómez-Hernández (2015), modificar parámetros deficitarios y marginalistas para asumir la diversidad social, recuperar para la praxis el conocimiento creado por fuera de lo científico y otorgarle reconocimiento, como otras formas de comprender el mundo.

\section{Pluralidad teórica y conceptual en la intervención profesional}

En línea con lo anterior, para la intervención profesional, los trabajadores(as) sociales recuperan aportes de diversas teorías: la educación popular, buen vivir, educación sistémica, constructivismo y fenomenología. Si bien éstas en su mayoría se enmarcan en una matriz comprensiva, crítica y decolonial como ya se había planteado, también fue posible encontrar en algunos casos puntuales, la referencia explícita de autores y teorías relacionadas con un enfoque explicativo. Lo anterior referido a los aportes del conductismo para el manejo de rutinas con jóvenes que tienen alguna discapacidad cognitiva, como se observa en el siguiente relato: 
...También se maneja aquí por la condición de discapacidad en los chicos, el enfoque conductista, o sea, porque son estimulo, respuesta, es trabajo muy de rutinas diarias... (actor 6, Comunicación personal, 10 de mayo 2019)

Podría plantearse que la intervención profesional, orientada desde este modelo, es de corte funcionalista y adaptativa (Vélez-Restrepo, 2003), se encarga de atender el aquí y el ahora, privilegiando el método de casos. Es importante reconocer que tal perspectiva, relacionada con un trabajo social clásico, puede considerarse aún vigente y según la experiencia de algunos profesionales, necesaria para el abordaje de situaciones particulares. Lo anterior lleva a considerar que, a nivel teórico y metodológico, algunos trabajadores sociales hacen uso de diversos referentes para construir su práctica, la cual sitúan en marcos epistemológicos diversos y en algunos casos opuestos, de allí la importancia de la vigilancia epistemológica, como ejercicio que promueva la reflexión, cuestionamiento y resignificación de las teorías. Según Cifuentes-Gil (2009, p. 62) citando a Vélez-Restrepo (2003) "es una tarea urgente a nivel profesional, asumir una actitud crítica, la cual permita analizar las implicaciones prácticas que determinadas nociones, concepciones y rutinas le imponen al accionar profesional". Así mismo, es necesaria la reflexividad como capacidad básica para la intervención, que permite asumir de manera crítica y fundamentada las decisiones tomadas en la práctica, buscando su articulación a los principios y fines de la profesión.

Lo anterior, porque si bien el Trabajo Social es una profesión que tiene como horizonte teleológico la transformación de un orden social que perpetúa las desigualdades sociales, las injusticias y la vulneración de derechos, no se encuentra una única forma de ser trabajador social y hacer práctica profesional. El Trabajo Social es diverso y en medio de esas diversidades se camuflan propuestas de acción coloniales, que no reconocen las múltiples opresiones que padece la población: mecanicistas, institucionalizadas, burocráticas y poco comprometidas que perpetúan y reproducen dinámicas hegemónicas de poder.

En este sentido es necesario, sin caer en un eclecticismo, que los y las profesionales retomen diferentes perspectivas -feministas, poscoloniales, críticas, entre otras- para fundamentar su práxis, ya que no es posible abordar la realidad desde un solo marco de referencia, como tampoco es posible prescindir de ellos y caer en un activismo irreflexivo que desdibuja el horizonte transformador del Trabajo Social.

Si bien fue posible reconocer en los encuentros conversacionales una relación manifiesta entre teoría y práctica por parte de los y las profesionales que formaron parte de este proceso investigativo, llama la atención encontrar en uno de los relatos, un aparente distanciamiento con los saberes, teorías y diversos referentes formativos ofrecidos desde el Trabajo Social y las ciencias sociales: 
...De pronto a veces rescataba eh como de algunas cositas de investigación, eh como el tema de las entrevistas o de las encuestas, pero como tal de la teoría que yo diga es que me estoy basando en algún eh no, de pronto al principio cogí el libro de Mary Richmond y miré todo el tema de tipologías familiares y ahí me volví, repasé todo el tema de nuevo para genogramas que en el hospital no usamos genograma, pero pues yo quería como al principio aplicarlo pensando que tenía poquito trabajo pero no, fue imposible porque los pacientes son muy cambiantes, todos los días yo tengo seis ingresos que para hacer entonces es complicado, pero entonces de ella fue como la única que tomé del libro algunas cositas pero como tal una teoría no, ya es como desde la parte médica. (actor 8, Comunicación personal, 27 noviembre de 2018)

Esta situación, generada en algunos casos por demandas y dinámicas institucionales, podría referir una pérdida de identidad profesional, la cual implica alejarse del propio saber especializado, para retomar el de otras disciplinas y desde allí fundamentar la intervención. En consecuencia, ésta termina siendo rápida, concreta y eficiente en el cumplimiento de las metas trazadas institucionalmente, pero distante de las discusiones teóricas, metodológicas y ético-políticas construidas a nivel profesional.

La brecha entre teoría y práctica forma parte de un debate histórico y vigente, sobre el cual Grassi (2007, p. 27) argumenta la existencia de una “clásica suposición de que los trabajadores(as) sociales se ocupan de problemas concretos (...) de aquellos que, sin lugar a dudas, afectan a la gente, y no de estudiarlos". En esta línea, algunas prácticas profesionales se debaten entre el practicismo y el teoricismo. En consecuencia, es posible encontrar profesionales que se ubican exclusivamente en el plano de la ejecución y, en otros casos, profesionales que manifiestan interés por establecer una relación dialéctica entre teoría y práctica pero encuentran como obstáculo su poca pertinencia y utilidad para dar respuesta a la compleja y cambiante realidad social a la que se enfrentan.

\section{Cuestionar y problematizar la teoría}

Frente a la situación anteriormente esbozada, resulta importante destacar la capacidad de problematización del profesional, que le permita, como ya se había mencionado, hacer vigilancia epistemológica de sus prácticas e interpelar las teorías que retoma, para posicionarse de manera diferente ante el conocimiento y así generar desde su propio discurso, renovadas comprensiones y conceptualizaciones (Zemelman, 2005) que sean más acordes a los desafíos de la práctica contemporánea. Al respecto el siguiente relato:

Y digo que va en doble vía porque también hay un tema de la universidad y es que yo siento primero que en cuanto a las teorías no estamos ni siquiera abordando teóricos latinoamericanos, nos estamos dedicando a teorías de hace muchísimos años y de autores que ni siquiera conocen nuestro contexto, que ni siquiera conocen nuestras realidades... (Actor 2, comunicación personal, 10 de octubre de 2019) 
Fue posible encontrar una actitud de búsqueda, reflexión y duda frente a la teoría por parte de los y las profesionales. Lo anterior es relevante, ya que cuestionar y problematizar los fundamentos teóricos de la práctica, demuestra una actitud crítica, inquieta y propositiva frente al conocimiento; conversar con los autores más que repetir sus postulados, les permite recuperar aportes relevantes para una intervención situada y comprensión compleja de lo social.

En esta línea, conocer discusiones contemporáneas que emergen de contextos locales, latinoamericanos, es una opción transgresora del paradigma dominante -actualmente vigente- para interpretar la realidad social. Según De Sousa-Santos (2009, p. 18), “en términos científicos vivimos todavía en el siglo XIX y el XX todavía no comenzó, ni tal vez comience antes de terminar." Es por esto que, siguiendo al autor, se hace un llamado a transitar hacia un paradigma emergente, conformado por conocimientos locales, diversos, construidos según intereses y necesidades por "grupos sociales concretos, con proyectos de vida" (p.49) particulares. De aquí la necesidad de hacer lecturas renovadas de los contextos en los que el o la trabajadora social interviene, buscando marcos teóricos coherentes con las múltiples realidades y situaciones que enfrenta en su práctica.

Reconocimiento de saberes propios de los grupos poblacionales con los que se interviene

Teniendo en cuenta lo anterior, uno de los desafíos actuales que enfrenta el trabajador social es la permanente reconfiguración de los fundamentos conceptuales y metodológicos que orientan su intervención, para construir una praxis más humana y menos instrumental, que reconozca lo diverso y lo diferente como potencia y no como amenaza. De allí que sea necesario, establecer relaciones respetuosas y horizontales con las poblaciones, para reconocer sus saberes y conocimientos como fuentes de aprendizaje:

\footnotetext{
(...) me pasaba digamos que con los indígenas hay un vínculo increíble con el territorio, eso es indiscutible y empecé a aprender un poco que territorio no necesariamente estaba enmarcado en la parte física donde ellos vivían sino que venían acá y íbamos a hacer una reunión y declaraban por un momento territorio la reunión o la oficina; entonces ya era claro, ya era poder de la guardia de ellos, ya estaba el ejercicio espiritual; cuando empiezo con el ejercicio afro también me doy cuenta que el territorio era muy importante pero que el territorio para ellos era más corporal (...). (Actor 3, comunicación personal, 19 diciembre de 2018)
}

El reconocimiento "del otro", como sujeto portador de conocimiento, es uno de los aspectos referidos por los y las profesionales al momento de abordar los asuntos teóricos de la intervención. Ello es relevante en tanto permite empezar a saldar la deuda histórica que se tiene con los saberes y formas de conocer "otras", construidas por seres humanos que han sido homogenizados, desconocidos y vulnerados. De aquí, la imperiosa necesidad de escuchar las otras voces que hasta ahora han circundado en los márgenes de los metarrelatos de la modernidad y todo aquello que ha sido deliberadamente invisibilizado y oculto, en 
pro de la homogenización del mundo. Reconocer los saberes de los grupos poblacionales con los que se interviene, requiere interpelar y cuestionar el paradigma racional, positivo, moderno, como única vía para conocer, dando cabida a otros que incluyan lo subjetivo, lo emocional y el conocimiento contextualizado; saberes que emergen de las prácticas y de la experiencia como legado intelectual de los pueblos pertenecientes a Latinoamérica y el Caribe.

\subsection{Aspectos metodológicos para la intervención profesional con comunidades diversas}

La metodología es considerada un componente fundamental de la intervención en Trabajo Social. Contempla supuestos teóricos, epistemológicos y métodos que orientan la acción y permiten alcanzar los fines (Cifuentes-Gil, 2004) o metas trazadas en el proceso de planeación de la práctica. Lo metodológico, a su vez, integra una dimensión ideológicopolítica, ética y contextual (Cifuentes-Gil, 2004) que le confiere especificidad. Ello implica la reflexión y decisión acerca de los saberes, teorías, epistemes, principios éticos y fundamentos políticos que guiarán la acción y serán más acordes para abordar el objeto de intervención y conocimiento de la praxis. En coherencia con estas cuestiones, la metodología también contempla asuntos de orden operativo, referidas a las estrategias, actividades, técnicas e instrumentos con los que se lleva a cabo el proceso de intervención.

Los asuntos hasta acá esbozados dan cuenta de lo metodológico como un componente robusto y de impacto para la praxis, como una impronta de la intervención, construida por los y las profesionales, a partir de su reflexión, creatividad, decisiones contextuadas y conscientes sobre sus componentes principales: teóricos, éticos, políticos y operativos. Por tanto, es un reto trascender la mirada reduccionista que a veces se asigna a la metodología a nivel profesional, en tanto la limita al plano de lo operativo e instrumental, sin contemplar los demás componentes centrales que le confieren rigor y sistematicidad.

En este orden de ideas, es necesario reconocer el lugar que ocupa la reflexión metodológica de la praxis a nivel profesional, toda vez que al asignarle un carácter residual y desconocerla como dimensión determinante de la intervención profesional, pueden construirse acciones poco reflexivas, transformadoras, distantes de los principios y fines del trabajo social y en algunos casos, perpetuar a través de la praxis, una visión deficitaria de los sujetos, relaciones de poder, asimetrías, desconocimiento de otros saberes sobre el mundo (De Sousa-Santos, 2009, p. 37) y demás consecuencias que se derivan de la estructura colonial vigente.

Por ello, es relevante construir propuestas metodológicas que fundamenten la acción profesional desde la reflexión y la crítica, que den cabida a lo creativo y novedoso para acercarse a la realidad social, a los grupos poblacionales, y promover su reconocimiento y 
agencia a través de diversas herramientas, estrategias, técnicas contextualizadas y enraizadas. Al conversar sobre el componente metodológico en la investigación, fue posible develar lo siguiente:

\title{
Metodología participativa y experiencial para la intervención profesional
}

Los trabajadores(as) sociales, desde su experiencia profesional con diversidades sociales, prefieren otorgar importancia a los procesos participativos y experienciales, al igual que a los métodos genéricos para su intervención:

\begin{abstract}
Bueno, metodológicamente lo hemos hecho pues, uno a través de, digamos de manera muy participativa, entonces dándole como la voz también al grupo y retomando lo que se va generando como en esos encuentro, en esas discusiones; círculo de la palabra yo creo que se dan en ambos espacios, siempre estamos como centrados a que el espacio es de todos y todas, entonces pues si es como un espacio de empoderamiento, de que las personas participen, de que digamos que tienen una voz y su voz es importante. (Actor 1, Comunicación personal, 15 de abril de 2019)

(...) también la planifico, entonces cuando sé el caso lo planeo completamente, preguntar acerca del esposo, los lazos familiares o si tienen conflicto con una persona con drogas entonces como es esa relación, lo único que hago siempre es como planear. (Actor 5, Comunicación personal, 15 abril de 2019)
\end{abstract}

Si bien los y las profesionales no manifiestan explícitamente la filiación a una corriente teórica o propuesta metodológica particular del trabajo social, desde su experiencia desarrollan procesos de inserción, planeación y evaluación que les permitan monitorear y hacer un abordaje diferenciado y particular de los casos o situaciones que intervienen, además de recuperar en estos espacios el protagonismo y voz de los sujetos, a partir de diferentes estrategias, técnicas y actividades que han validado en la práctica.

La participación y el componente experiencial como parte de lo metodológico, tiene conexión con las perspectivas comprensivas y críticas referidas por los y las profesionales en la dimensión epistemológica y teórica de sus prácticas. Entre tanto, desde ellas se privilegia para el abordaje de lo social, lo subjetivo, la reflexión, la escucha y la comprensión. Estas pistas que ofrecen los y las profesionales acerca de lo metodológico como participación, responden a una mirada democrática que reconoce el valor del trabajo colaborativo, lo cual a su vez les otorga un papel protagónico, epistémico y político a los sujetos de la intervención y trasciende su mirada carencial y deficitaria.

Sin embargo, unido a lo anterior, también fue posible reconocer a partir de los encuentros conversacionales, que la dimensión metodológica de sus prácticas se enmarca principalmente en asuntos de orden técnico e instrumental, sin lograr mayor discusión acerca de los asuntos teóricos, éticos, políticos que las orientan. Ello implica la necesidad de fortalecer en escenarios de formación profesional -como encuentros, congresos, simposios, agremiaciones, semilleros y pregrado- la discusión y resignificación de la metodología 
como asunto estructurante de la praxis profesional, lo cual permitiría consolidar propuestas de intervención pensadas, reflexivas, que hagan frente a las demandas del contexto, aporten al interés transformador de la práctica y tributen al fortalecimiento de la identidad profesional, desde el conocimiento y problematización de la acción.

\title{
Estrategias, técnicas y actividades para la intervención
}

En coherencia con lo planteado, las estrategias construidas por los trabajadores(as) sociales para la intervención, son lúdicas, participativas, artísticas y de corte vivencial. Las técnicas rescatadas son la cartografía social, el dibujo, los talleres, visitas, juegos de roles, danza, fotografías y, como actividades, tertulias, encuentros, rituales, mandalas y ejercicios de escucha y escritura:

\begin{abstract}
(...) planeamos desde la IAP el ejercicio para conocerlos, indígenas, afros, si lo planeé desde ahí, me devolví, la cartografía me gustaba mucho porque cuando ellos empezaron a hablar de territorios (...) ellos mismos hicieron un mapa increíble (...). Con el pueblo Pijao hicimos un y dejamos un texto escrito y de imagen tratando de ubicar también tres sitios sagrados que parte de una cartografía que hicimos. (Actor 3, Comunicación personal, 19 de diciembre de 2018)

Desde la danza porque yo a ellos no les puedo como decir, escríbame esto, aparte porque todos están desescolarizados, no saben escribir, no saben leer y por eso utilizo, puedo decir que es una fortaleza, la danza desde la expresión corporal. Entonces esa es la manera en la que yo puedo como interactuar con ellos y en la que ellos se sienten cómodos y como que no se sienten juzgados, sino que ellos pueden ser ellos mismos a través de su cuerpo; sin ser juzgados. (Actor 9, Comunicación personal, 14 de diciembre de 2018)
\end{abstract}

Estas experiencias compartidas por los y las profesionales, revelan una disposición hacia metodologías otras, novedosas, no tradicionales ni directivas, que invitan a "sobrepasar el peso colonial de que lo escrito es lo que existe, (...) para abrirnos a la creatividad que otorga aprender nuevos lenguajes que han sido menospreciados como medio comunicativo" (Gómez-Hernández, 2015, p. 9). Este es el caso de propuestas como el dibujo, fotografía, danza rituales y juegos, que responden a metodologías diferenciadas y acordes a las diversidades sociales con las que interactúa el Trabajo Social en su práctica.

Por esta razón, es un desafío pensar cómo las técnicas, instrumentos y estrategias recuperadas en el hacer profesional, pueden estar ancladas a prácticas coloniales, desconociendo las diversidades, saberes y aportes de los sujetos que forman parte de las prácticas. Las pedagogías decoloniales pueden aportar herramientas y reflexiones importantes para avanzar en este campo, principalmente invitando a la deconstrucción de procesos educativos tradicionales que responden a discursos modernos, hegemónicos y homogéneos y desconocen las raíces, lo relacional y la escucha como posibilidad de construir diálogos interculturales. Tales diálogos, construyen "valores comunes compartidos, más allá de la legítima diversidad de las culturas... lo cual implica un sentido 
ético, ya que permite que los participantes lleguen a una comprensión mutua" (Jahanbegloo, 2015, p. 14).

\subsection{Dimensión ética y política que orienta la intervención profesional con comunidades diversas $^{4}$}

La dimensión ética y política en Trabajo Social es una discusión vigente y necesaria en escenarios académicos y profesionales, por su relación con el cumplimiento efectivo de los principios y fines que orientan la praxis. Con respecto a este tema, fue posible encontrar:

Con respecto a los principios éticos que orientan la intervención profesional, la escucha, el respeto y el reconocimiento de la otredad, fueron aspectos referidos de manera general por los y las profesionales, independientemente del lugar donde se desempeñen. Reconocer al otro, como diverso, pero a su vez los recursos con los que cuenta y aportes que realiza, permite valorar la diferencia, lo cual es clave para construir diálogos interculturales (Guerrero-Arias, 2010b).

El respeto por la diferencia propia y del otro, permite un ambiente de convivencia para asumir lo diverso como potencia. La escucha cobra relevancia, porque motiva la empatía, ésta implica ocupar el lugar del otro, establecer relaciones de paridad y transitar de una perspectiva de lo individual a lo colectivo -nosotros (Lenkersdof, 2008).

En cuanto a los dilemas éticos en la intervención, las situaciones laborales y el desacuerdo en prácticas culturales, según los y las profesionales son asuntos de difícil abordaje. Las situaciones contractuales, ponen en juego su autonomía y posibilidad de decisión. Algunos trabajadores sociales, tienen relaciones de subordinación y dependencia en sus espacios laborales, lo que les resta posibilidades de acción (Aquín, Custo y Torres, 2012).

(...) en el sitio por ejemplo en el que estuve el año pasado a usted lo miden por usuarios atendidos, entonces si usted no cumple con la cantidad de usuarios entonces usted no es tan buena... (Actor 11, comunicación personal, 22 de noviembre de 2018)

Todo lo contrario se presenta cuando los y las profesionales acompañan iniciativas gestadas desde intereses colectivos y no existen condicionamientos contractuales, aumenta la autonomía y la posibilidad de una intervención creativa. Esta situación invita a debatir

4 En este apartado se presenta un resumen de los resultados, acerca de la dimensión ética y política de la intervención profesional, ya que estos fueron presentados de manera completa en una ponencia titulada "Ética decolonial e intercultural: reflexiones desde la intervención profesional que realizan Trabajadores Sociales egresados de la Universidad del Quindío, con comunidades diversas" en el Seminario Internacional sobre ética intercultural y decolonial llevado a cabo el 1 y 2 de octubre del 2019 en la Universidad de Antioquia (Medellín, Colombia) y forman parte de las memorias del evento. 
en las organizaciones y agremiaciones profesionales asuntos referentes a la praxis para establecer puntos de encuentro entre intereses académicos, personales y políticos.

Así mismo, la conflictividad proveniente de las diversas formas de comprender el mundo, “(...) los esquemas valorativos y normativos distintos", (Salas-Astrain, 2006, p. 39), propios de cada cultura, es un dilema y reto presente en la intervención profesional. Como ejemplo de ello una de las profesionales planteaba su incomodidad al no poder escuchar las voces de las mujeres, los niños y las niñas: “...Ellas no pueden opinar..." (Actor 4. Comunicación personal, 30 de noviembre de 2018). La ética intercultural, según SalasAstrain (2006) invita a convivir, compartir, desde las valoraciones diversas, reconociendo obstáculos y retos para la comunicación; reconocer las diferencias sin idealizar o romantizar acciones que provienen de ciertas culturas (León-Díaz, 2007).

De otro lado, los sujetos de la intervención se asumen desde sus derechos, capacidades y conocimientos. Observándose una disposición entre los y las profesionales a trascender visiones carenciadas del otro, hacia miradas que rescatan la potencia, lo diverso y el protagonismo. A pesar de ello, es común encontrar que los impactos de la modernidad en los discursos colectivos conllevan a asumir un ideal de sujeto universal y homogéneo que influye en las relaciones, sin que se tenga mayor consciencia de ello.

Con respecto a lo relacional, fue posible encontrar que los y las profesionales construyen relaciones cercanas y de confianza en los procesos de intervención, establecen relaciones colaborativas y respetuosas, lo cual permite trascender el autoritarismo y fortalece capacidades de autonomía. Los aportes de las pedagogías decoloniales en esta línea, son importantes para la intervención profesional, en tanto ponen en tensión el poder que tiene el saber científico sobre los saberes populares e invitan a una postura de reconocimiento en la conversación, ya que "las voces asimétricas, no pueden reconocerse" (Salas-Astrain, 2006, p.34). Cabría preguntarse entonces si se han reproducido históricamente diálogos asimétricos entre culturas, entre pueblos, que han llevado a la dominación de unas sobre otras.

En cuanto a la dimensión política desde la intervención profesional, se destaca en los relatos de los y las profesionales que el Trabajo Social aporta a la construcción de un proyecto político cimentado en la formación de sujetos críticos, reflexivos, autónomos, que se movilicen a participar en los asuntos que les conciernen, comprometidos de esta forma con la construcción de país:

...El tema de empoderamiento, (...) de asumirse como actores y con posibilidad de cambio (...). (Actor 1, comunicación personal, 15 de abril de 2019) 
Aportar a la formación de sujetos políticos, requiere la apropiación, exigencia y lucha por los propios derechos y la búsqueda colectiva de un mundo más justo y equitativo para todos. La discusión de la dimensión política en clave decolonial deberá contemplar la recuperación y la escucha de voces negadas, que no se han ajustado a las dinámicas aceptadas por la modernidad. Por lo tanto, implicaría reconocer y rescatar, otras formas de vivir y habitar, que han sido ocultadas, controladas y/o excluidas (Vázquez y BarreraContreras, 2016).

\section{Conclusiones}

Realizar un proceso investigativo, teniendo como referente la opción decolonial e intercultural, conlleva como principal desafío deconstruir antiguas prácticas y reconfigurar acciones "otras" para conocer, pensar y construir colectivamente. Implica darle paso a la incertidumbre y atreverse a renombrar, pero principalmente a reconocer las herencias coloniales que nos habitan y que permean la investigación. El camino es largo, requiere compromiso, apertura y aventurarse a transitarlo desde la convicción. En coherencia, abordar los componentes centrales de la intervención profesional desde esta perspectiva, le permite al Trabajador Social, ser consciente de su propia colonialidad y cómo ésta permea su ejercicio profesional, a nivel teórico, metodológico y ético político. Reconocer estas marcas le permiten un actuar profesional más pertinente con las demandas del contexto y con el horizonte emancipatorio, de justicia, dignidad y garantía de derechos que orienta la praxis. Teniendo en cuenta este marco de referencia, las reflexiones y hallazgos que emergieron de este proceso, impulsan la discusión endógena disciplinar, sobre los componentes que deben ser problematizados en la formación curricular de los futuros Trabajadores(as) sociales, invitando a revisar la pertinencia de las mallas curriculares de los programas académicos en las diferentes escuelas. Lo anterior, teniendo en cuenta que el giro epistemológico vivido actualmente en las Ciencias Sociales, permea las discusiones profesionales, las dinámicas universitarias y, por ende, conlleva a la necesidad de reconocer formas plurales de conocer, conectadas con las realidades sociales del país y del contexto Latinoamericano y Caribeño. Ello implica la apertura a un diálogo intercultural desde el cual se reconozcan las diversidades sociales y "la compleja trama de relaciones interculturales que nos constituyen" (Mosquera-Rosero, 2005, p. 269).

Teniendo en cuenta lo anterior, los aportes que se consideran relevantes para aportar al debate acerca de la intervención profesional con diversidades sociales, desde las dimensiones teórica, metodológica, y ético-política son las siguientes:

\section{Con respecto a la dimensión epistemológica y conceptual}

Es necesario fortalecer el trabajo colectivo a nivel profesional, desde las agremiaciones, grupos de estudio, semilleros e investigaciones propiamente dichas, con el fin de 
problematizar los fundamentos teóricos y epistemológicos que fundamentan las prácticas profesionales, buscando que estos sean diversos, plurales y más acordes a la situación actual del contexto nacional y Latinoamericano. En esta misma línea, hacer una revisión permanente de la formación académica del Trabajo Social y de las mallas curriculares, de los programas académicos, revisando su pertinencia con respecto a los múltiples saberes, formas de construcción de conocimiento y diversidades sociales en resistencia. Sin embargo, también es importante motivar a los y las trabajadoras sociales y estudiantes en formación, en la construcción de un pensamiento epistémico que problematice la teoría al tenor de los desafíos en lo social. Si bien es clara su relevancia para la praxis, la complejidad de las situaciones presentes en la intervención conlleva una necesaria interpelación de los referentes o categorías teóricas desde las cuales se comprende la realidad social, aventurándose a crear nuevas formas de comprender (Zemelman, 2005). Se requiere, por tanto, fortalecer una actitud crítica, propositiva y creativa que permita a los sujetos cuestionar las teorías, no asumirlas como acabadas e inscribirse en una lógica de reflexión y vigilancia permanente sobre los fundamentos que sirven de base a su intervención. Para avanzar en esta idea, el desafío es descolonizar las posturas epistémicas y metodológicas desde las cuales se ha orientado su acción y abrirse a la posibilidad de conversar con otros conocimientos, que emergen de los pueblos y comunidades con los que interactúa.

\section{En cuanto a los aspectos metodológicos}

A través de la historia del Trabajo Social, la metodología ha ocupado un lugar relevante, en tanto es referente y guía de la acción. Diferentes discusiones y desarrollos a nivel profesional se han gestado, buscando que ésta sea acorde a las problemáticas y situaciones que aborda el trabajador social, pero también a su especificidad profesional ${ }^{5}$. Evidencia de ello es la vasta producción académica enfocada en métodos (genéricos, únicos, polivalentes, integrados) y modelos (psicodinámicos, sistémicos, críticos), clásicos y contemporáneos que son referente de la intervención. A partir de este ejercicio investigativo, se plantea la necesidad de continuar el debate acerca de la metodología a nivel profesional, con el fin de evitar una mirada residual o reduccionista de la misma. Así mismo, es relevante contemplar los aportes que ofrece la pedagogía decolonial y la interculturalidad, para abordar las diversidades sociales con las que el Trabajo Social interactúa, motivando la consolidación de metodologías otras que transgredan las lógicas desarrollistas y homogenizantes que desconocen los saberes locales, y la diversidad de prácticas culturales propias de los contextos. Para dar cabida a discusiones decoloniales en la intervención profesional $\mathrm{y}$, específicamente en dimensiones como la metodológica, es necesario

5 La especificidad en lo metodológico no tiene una pretensión homogenizante, en tanto se reconoce el carácter plural del actuar profesional. Más bien hacer referencia en el marco de lo diverso de la praxis, a lo que resulta distintivo y característico en el Trabajo Social. 
promover la consolidación de currículos interculturales, cuyos ejes transversalicen las mallas y hagan parte de la vida académica universitaria.

\section{Desde el componente ético politico}

La discusión acerca de lo ético-político en la intervención profesional es un asunto central para la formación de Trabajadores Sociales; sin embargo, la reflexión del primer aspecto se ha enfocado en las directrices ofrecidas por el código deontológico y el segundo ha tendido a diluirse o a quedarse en el plano de lo discursivo. Esto es necesario replantearlo desde las mallas curriculares y actividades académicas, para problematizar, ampliar la comprensión y abordar los múltiples componentes que involucra. Así mismo, desde los procesos de intervención con diversidades sociales, es necesario reflexionar desde lo ético, acerca de las tensiones y conflictos que emergen por las diferentes visiones de mundo. Considerar la discusión profesional de una ética relacional y pragmática, que implique el reconocimiento de acciones propicias para relacionarnos asertivamente con las diversidades, es necesario en el contexto actual. Las pedagogías decoloniales tributan a esta reflexión y al reconocimiento de sujetos localizados, enraizados. Incorporar estrategias pedagógicas decoloniales en la formación académica, en los procesos de intervención y en la discusión sobre lo ético-político, posibilitará vivir la diversidad como característica central de lo humano y como base para la construcción de diálogos interculturales que potencien la construcción de proyectos políticos profesionales orientados a la transformación social de las múltiples opresiones padecidas.

\section{Referencias bibliográficas}

Aquín, N., Custo, E., y Torres, E. (2012). El problema de la autonomía en el Trabajo Social. Plaza Pública. Revista de Trabajo Social, 5(8), 304-320.

Carballeda, A. J. (2005). La intervención en lo social: exclusión e integración en los nuevos escenarios sociales. Buenos Aires: Paidós.

Cifuentes-Gil, R. M. (Julio, 2004). Aportes para "leer" la intervención de Trabajo Social. En XVIII Seminario Latinoamericano de escuelas de Trabajo Social: la cuestión social y la formación profesional en Trabajo Social en contexto de las nuevas relaciones de poder y la diversidad Latinoamericana. Asociación Latinoamericana de Escuelas de Trabajo Social-ALAEITS. San José, Costa Rica.

Cifuentes-Gil, R. M. (2009). Consolidación disciplinar de Trabajo Social en las ciencias sociales: desafío y horizonte en la formación profesional en Colombia. Eleuthera, 3, 40-71.

Corvalán, J. (1996). Los paradigmas de lo social y las concepciones de intervención en la sociedad. Recuperado de http://surmaule.cl/wpcontent/uploads/sites/4/2014/12/Corvalan-J.-Los-paradigmas-de-lo-social.pdf.

Fals-Borda, O. (2009). Una sociología sentipensante para América Latina. Bogotá, Colombia: Siglo del Hombre Editores. Clacso. 
Gómez-Hernández, E. (septiembre, 2015). Trabajo Social Decolonial. En XXI Seminario Latinoamericano de Escuelas de Trabajo Social la formación profesional en Trabajo Social: Avances y tensiones en el contexto de América Latina y el Caribe. "A 50 años del Movimiento de Reconceptualización", Asociación Latinoamericana de Enseñanza e Investigación en Trabajo Social-ALAEITS, Mazatlán, México. Recuperado de https:/ / docer.com.ar/doc/s0vx511.

Grassi, E. (2007). Problemas de realismo y teoricismo en la investigación social y en el Trabajo Social. Revista Katálysys, 10(esp.), 26-36. Recuperado de https:/ / www.scielo.br/j/rk/a/Ymp6MtvQ7yFkqVnLWxQb6ZB/?format=pdf\&lan $\mathrm{g}=\mathrm{es}$.

Guerrero-Arias, P. (2010a). Corazonar, una antropología comprometida con la vida: miradas otras desde Abya-Yala para la decolonización del poder, del saber y del ser. Quito, Ecuador: Ediciones Abya-Yala.

Guerrero-Arias, P. (2010b). Corazonar el sentido de las epistemologías dominantes desde las sabidurías insurgentes, para construir sentidos otros de la existencia (primera parte). Calle 14. Revista de investigación en el campo del arte, 4(5), 80-94. Recuperado de https:/ / revistas.udistrital.edu.co/index.php/c14/article/view/1205/1596.

Jahanbegloo, R. (2015). Paz e interculturalidad. Medellín: Universidad Eafit.

Lenkersdof, C. (2008). Aprender a escuchar. Enseñanzas Maya Tojolabales. México: Plaza y Valdés.

León-Díaz, R. (2007). Trabajo Social intercultural. Algunas reflexiones a propósito de la intervención con una comunidad indígena del Trapecio Amazónico Colombiano. Palobra. Palabra que obra, (8), 200-220. Recuperado de https://revistas.unicartagena.edu.co/index.php/palobra/article/view/231/191.

Maldonado-Torres, N. (2007). Sobre la colonialidad del ser: contribuciones al desarrollo de un concepto. En S. Castro-Gómez y R. Grosfogüel (Comps.), El giro decolonial. Reflexiones para una diversidad epistémica más allá del capitalismo global. (pp. 127-167). Bogotá, Colombia: Siglo del Hombre Editores.

Maldonado-Torres, N. (2009). El pensamiento filosófico del "giro descolonizador". En E. Dussel, E. Mendieta, y C. Bohórquez (Eds.), El pensamiento filosófico latinoamericano del Caribe y "Latino" [1300-2000]. Historias, corrientes, temas y filósofos (pp. 683-697). México: Siglo XXI.

Matus-Sepulveda, T. (2002). Propuestas contemporáneas en Trabajo Social. Hacia una intervención polifónica. Buenos Aires: Espacio Editorial.

Mignolo, W. (2010). Desobediencia epistémica: retórica de la modernidad, lógica de la colonialidad y gramática de la descolonialidad. Buenos Aires, Argentina: Ediciones del signo.

Mosquera-Rosero, C. (2005). Pluralismos epistemológicos: hacia la valorización teórica de los saberes de acción. Una reflexión desde la intervención social de la población afrocolombiana desplazada. Palimpsestvs, (5), 262-276. Recuperado de https:/ / revistas.unal.edu.co/index.php/palimpsestvs/article/view/8080/8724. 
Ortiz-Ocaña, A., y Arias-López, M. I. (2019). Hacer decolonial: desobedecer la metodología de investigación. Hallazgos, 16(31), 147-166. doi: 10.15332/s1794-3841.2019.0031.06.

Rozas-Pagaza, M. (2002). Una perspectiva teórico metodológica de la intervención en Trabajo Social. Argentina: Espacio Editorial.

Salas-Astrain, R. (2006). Ética Intercultural. Ensayos de una ética discursiva para contextos culturales conflictivos. (Re) Lecturas del pensamiento latinoamericano. Quito, Ecuador: Ediciones Abya-Yala.

Sousa-Santos, B. De. (2009). Una epistemología del sur: la reinvención del conocimiento y la emancipación social. México: Siglo XXI editores.

Travi, B. (2006). La dimensión técnico-instrumental en Trabajo Social: reflexiones y propuestas acerca de la entrevista, la observación, en registro y el informe social. Buenos Aires, Argentina: Espacio Editorial.

Vélez-Restrepo, O. L. (2003). Reconfigurando el Trabajo Social. Perspectivas y tendencias contemporáneas. Buenos Aires, Argentina: Editorial Espacio.

Vazquez, R., y Barrera-Contreras, C. (2016). Aesthesis decolonial y los tiempos relacionales. Entrevista a Rolando Vázquez. Calle 14: revista de investigación en el campo del arte, 11(18), 76-93. Recuperado de: https:/ / www.redalyc.org/articulo.oa?id=279047494001.

Walsh, C. (2008). (De) colonialidad e investigación. Ética, práctica y saber. En I Encuentro Internacional y V Nacional de investigación. Universidad Libre, Bogotá, Colombia.

Zemelman, H. (2005). Voluntad de conocer: El sujeto y su pensamiento en el paradigma crítico. México: Anthropos. 


\section{OTROS ARTÍCULOS DE PROSPECTIVA No. 33}

\section{EDITORIAL}

El Paro Nacional en Colombia 2021: explosión social entre dinámicas estructurales y de coyuntura. Relevancia de la acción política y del diálogo en su desarrollo y transformación Adolfo Adrián Álvarez-Rodríguez

\section{ARTÍCULOS}

Organizaciones sociales de pobladores y prácticas de resistencia en contexto de pandemia COVID-19 en Chile

Patricia Castañeda-Meneses

Entre el aislamiento y las brechas digitales: sistematización de experiencia de acompañamiento socioemocional en personas mayores de Temuco, Chile, en tiempos de COVID-19

G. Bernarda Aedo-Neira

Percepción de apoyo social y calidad de vida: la visión de personas mayores chilenas en el contexto de pandemia durante el 2020

Claudia Elena Quiroga-Sanzana

Gabriela Rocío Parra-Monje

Camila Julia Moyano-Sepúlveda

Marco Alejandro Díaz-Bravo

A propósito del qué, cómo y para qué investigar en el campo de la justicia juvenil: La trastienda de un proceso de investigación en Rosario, Argentina Karina De Bella

Proyección social: reflexión sobre una experiencia virtual con adolescentes en época de pandemia en Sucre y Bolivar, Colombia

Claudia Yaneth Martínez-Mina
La intervención social mediante proyectos comunitarios en modalidad virtual en Mérida, México. Una perspectiva desde el Trabajo Social Claudia Isabel Tzec-Puch Amairani Aracelly Ceh-Alvarado Yanet Guadalupe González-Canul

Resignificación de los vínculos Sociales durante la pandemia de COVID-19: narrativas de personas que convergen en Conjuntos residenciales en Bogotá, Colombia

Andrea Marcela Reyes-García

Laura Daniela Molina-Ortiz

La paradoja de la familia doblemente recluida: clínica de una pandemia en Colombia

Norman Darío Moreno-Carmona

Juan José Cleves-Valencia

Ciencias sociales, mundo y pandemia: por un futuro posible

José Miguel Segura-Gutiérrez

Lina Paola Vásquez-Ávila

¿Qué es Trabajo Social? Los primeros vínculos de los estudiantes con la profesión: experiencias de Argentina, Brasil, Paraguay y Uruguay

Silvia Orieta Rivero-Rodríguez

Leonel Del Prado

Nidia Graciela Battilana-Amarilla

Rosilaine Coradini-Guilherme

Intervención profesional de trabajadores sociales de la universidad del Quindio, Colombia. Asuntos epistemológicos, metodológicos y ético-políticos

Ana María Gil-Ríos 
Reflexiones sobre la intervención social en lo rural: experiencias en el Magdalena Medio, Colombia

Claudia Milena Quijano-Mejía

Johana Linares-García

Construcción de rutas de atención integral a la convivencia escolar en Cali, Colombia: sistematización de la experiencia

Leidy Johana Prado-Montaño

Luz Helena López-Rodríguez

Alejandra Gutiérrez-Cárdenas

Experiencia del proceso de intervención familiar de los actores participantes en la Escuela para Familias del ICBF-Jamundí, Colombia Katherin Viviana Silva-Minotta

María José Forero-Izquierdo

Jimena del Pilar Jaramillo-Jaramillo

\section{RESEÑAS DE LIBROS}

Alerta global: políticas, movimientos sociales y futuros en disputa en tiempos de pandemia Jairo Crispín

El neoliberalismo como teología política. Habermas, Foucault, Dardot, Laval y la historia del capitalismo contemporáneo

José Francisco Desentis-Torres

La Reconceptualización del Trabajo Social en Colombia: Análisis histórico-crítico de las décadas de 1960-1970

Juan Pablo Sierra-Tapiro

ARTISTA INVITADO

Juan Camilo González

Prospectiva

\section{PROSPECTIVA}

Revista de Trabajo Social e Intervención Social

No. 33 • ene.-jun. 2022

e-ISSN: 2389-993X • Universidad del Valle 